\title{
NOTES ON ORTHOGRAPHY
}

Most Yiddish words, which are normally written using the Hebrew alphabet, have been transcribed according to the system of the YIVO Institute for Jewish Research, the closest thing in existence to a Yiddish academy. It's not perfect, but it's a decent middle path between a variety of Yiddish dialects. The most problematic aspect of this in practice is that ay makes the long $i$ sound, like pie. $K h$ is what it sounds like when you clear your throat. Also, an $e$ at the end of a word or name is pronounced $e$ h. Other than that, it's pretty straightforward. The point here is to allow readers of English to be able to pronounce Yiddish words as they're supposed to sound. Some people will probably be annoyed by the results.

Polish words have also been transliterated phonetically into English. Although this is totally unnecessary because Polish is written with the Roman alphabet, readers of English unfamiliar with the Polish orthographic system will undoubtedly look at a word such as czajnik with complete incomprehension, their heads cocked to the side like a dog hearing a high-pitched whistle. Because the bit of Polish that appears (street and town names mostly) comes from Yiddish sources, in which they appear phonetically, I use the YIVO system to transliterate them. As such, I would spell that same word tshaynik, which is a degree easier to read and to pronounce for readers of English. Just to see how far I could go, I briefly considered writing the entire book using YIVO orthography. Bot yu no, meybi its not sotsh a greyt aydiya efter ol. 
This page intentionally left blank 
BAD RABBI 
This page intentionally left blank 